Article

\title{
Reactor Design and Thermal Performance Analysis for Solar Thermal Energy Storage Application
}

\author{
Yabibal Getahun Dessie ${ }^{1}$, Bachirou Guene Lougou ${ }^{1,2, * \mathbb{D}}$, Hong Qi ${ }^{1, * \mathbb{C}}$, Heping Tan ${ }^{1}$, \\ Juqi Zhang ${ }^{1}$, Baohai Gao ${ }^{1}$ and Md Arafat Islam ${ }^{1}$ \\ 1 School of Energy Science and Engineering, Harbin Institute of Technology, Harbin 150001, China; \\ get_yabibal@yahoo.com (Y.G.D.); tanheping@hit.edu.cn (H.T.); zhangjq_hit@163.com (J.Z.); \\ 18846753664@163.com (B.G.); aisadaf7@yahoo.com (M.A.I.) \\ 2 MIIT Key Laboratory of Critical Materials Technology for New Energy Conversion and Storage, \\ School of Chemistry and Chemical Engineering, Harbin Institute of Technology, Harbin 150001, China \\ * Correspondence: 15bf02043@hit.edu.cn (B.G.L.); qihong@hit.edu.cn (H.Q.)
}

Received: 24 May 2020; Accepted: 17 June 2020; Published: 19 June 2020

\begin{abstract}
Solar energy is a sustainable and low-cost renewable energy of enormous importance, especially at this time where non-renewable energy sources are unsustainable and costly. However, improving the thermal performance of a solar energy storage reactor poses some challenges. In this study, the location of fluid inlets and outlets in the given reactor design and its impact on the thermal performance were investigated. A $\mathrm{P}_{1}$ approximation radiation model coupled with shallow channel approximation of fluid flow was developed. By taking the frustum base as a reference, four fluid inlets along the edges of the frustum and two outlet locations at the base and side of the reactor were computed. Inlets located $4.81 \mathrm{~cm}$ from the base of the frustum and an outlet located at the side of the reactor were found to have a better thermal performance with a short conveyer energy flow system. It was also deduced that radiation applied at the edges of the frustum had better thermal performance than that applied at a quartz edge. Furthermore, increasing the laminar inflow rate from $0.36(\mathrm{~L} / \mathrm{h})$ to $3.6(\mathrm{~L} / \mathrm{h})$ increased the temperature distribution in the reactor. This study provides noteworthy insights of relevance to the power engineering industry and academia.
\end{abstract}

Keywords: thermal performance; sustainable; solar energy storage; reactor design; temperature distribution

\section{Introduction}

The large dependence on non-renewable energy resources by countries for both domestic and developmental needs makes the enhancement of energy storage efficiency pertinent at this current time. There is increasing interest by stakeholders in the energy industry and researchers in minimising oil dependency by adopting other low-cost and eco-friendly energy alternatives. Moreover, environment-related issues due to the utilisation of non-renewable energy sources such as the emission of green-house gases are of increasing concern to researchers [1-4].

There are many renewable sources of energy, such as solar energy. Harvest and proper storage of solar energy can be used for many applications including high-temperature solar radiant energy flow, storage for power electric generation, production of hydrogen, and gasifying high carbonaceous via the high thermochemical process [5-14]. The production of electricity through the direct irradiation of a solar receiver is a contemporary topic for researchers because the need for boundary heat sources is increasing and people have attempted to extract the highest amount of energy from the sun. Researchers have done a lot to improve the efficiency of the solar receiver, solar fuel production, and solar thermochemical heat storage. However, the effective design of solar storage, thermal 
performance, long working hours of stored energy, and insulation material used in the solar storage device have a great impact on solar energy storage efficiency.

Recently, many technologies have been developed such as concentrating solar plants (CSP) and thermal energy storage (TES) technologies for the storage of energy. Thermal energy storage is a very important technology that has been used in heating and cooling, solar energy power production [15], environmental projects and other energy-saving sectors. TES has many advantages including the utilisation of non-renewable source energy, high dispatch performance, use during dark periods of the day, and its low cost when compared with electric power. However, solar energy is available only during the day and unavailable at night. Thus, the generation of energy in a dark or cloudy time is an issue $[16,17]$. Energy storage systems can be categorised into three energy fields namely latent heat, sensible heat and chemical storage. Sensible and latent heat storage are well-known technologies in CSP. Latent heat storage uses phase change materials (PCMs) [18,19]. LCM is used as a heat transfer media or energy storage media, which has wide applications due to their higher heat accumulation capacity $[20,21]$. In a solar storage system, the main factors are collection and conversion efficiencies. This implies that the cavity design, type of insulation material, fluid type, etc. have a great impact on flux distribution. In most cases, related technologies require temperatures of $1600 \mathrm{~K}$ and above. This is the reason why TES is still under investigation and development. Cavity design is the main factor in considering TES. Dimensions of cavity aperture optimisation, receiver diameter, inlet-outlet radius, inputs selection, thermal insulations and of reactant species, inlet velocity and pressure are factors that affect thermal performance for storage [22-24]. Solar irradiance heat flux and temperature distribution are also affected by the efficiency of the conversion of reactant species [25]. The residential time, reactant materials analyses for thermochemical storage and effective reduction ions are indicators for effective thermal performance and temperature distribution in the cavity. The main output from thermal energy storage is to achieve good thermal performance, stable temperature distribution, and maximisation of the outlet temperature for many applications.

Replete studies have examined the maximisation of solar energy and its application. The thermal efficiency of different geometric cavity receiver shapes was studied by Harris and Lenz [26] using a parabolic concentrator. The study revealed that the cavity receiver lost approximately $12 \%$ of the energy supplied to the receiver aperture and cavity geometry had a minor impact on overall performance. Reddy et al. [27] examined the impact of emissivity, inclination, thickness and operating temperature on natural, forced convection and radiation heat losses of a modified hemispherical cavity receiver and the result indicated minimum natural convection heat loss occurred for the open side of face downward receiver. Le Roux et al. [28] designed and implemented a modified cavity receiver composed of a parabolic dish concentrator in a small-scale concentration solar power system. They showed that channel length is affected by wind factor, rim angle, and concentration ratio and thermal receiver design have a significant effect on the net power output of the system. Prakash [29] also studied the natural convection heat losses of various cylindrical cavity receiver diameters using CFD simulations. The proposed model provided by the researchers included the heat transfer fluid (HTF) flow within a helical coil with air. They observed that an increase in convection loss is facilitated by an increase in the mean temperature of the HTF, whereas a decrease in convection loss is due to an increase in receiver inclination.

There is currently limited information on how and to what extent the location of fluid inlets on frustum edges affect the thermal performance of a solar rector with respect to the heat applied through quartz glass. Thus, this current study investigates the thermal performance analysis of energy storage reactor using shallow channel approximation fluid flow coupled to the $\mathrm{P}_{1}$ radiation model. The effect of carrier gas on inflow laminar rate, the influence of different fluid inlet locations along frustum edges and different fluid outlet locations, and impact of applied concentration radiation on the frustum boundary region and directed applied radiation flux on quartz glass edge for the storage medium were compared and investigated. The suitable dimensions in achieving the required outlet temperature 
and the optimal operating conditions in withstanding high-temperature intake and prediction of temperature distributions in the reactor were suggested.

\section{System Configuration}

Figure 1 demonstrates the path of how solar energy is harvested and used for energy derived utility. This figure was adapted from [30], which illustrated how concentrated solar energy reaches the surface of quartz glass and enters into the cavity of a reactor. It also shows how hot steam is taken for power utility purposes. After hot steam is taken, cold fluid flows back through the ladder into the inlet tubes of the reactor.

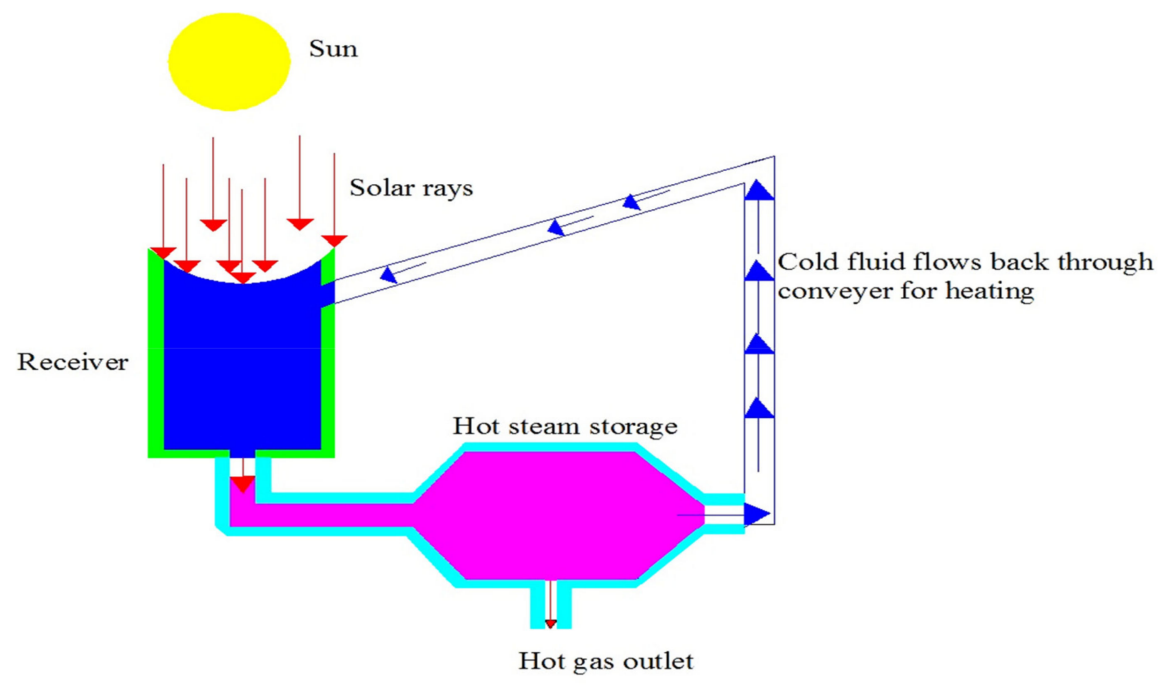

Figure 1. Energy flow system. Adapted from [30].

\section{Reactor Model}

\subsection{Physical Model}

Figure 2 illustrates the proposed heat storage reactor model. Figure 2a indicates the edges of external boundaries, inlets, irradiated walls, and the quartz glass boundary. Figure $2 \mathrm{~b}$ shows the $2 \mathrm{D}$ schematic diagram of the proposed solar thermal energy used for the numerical simulation.

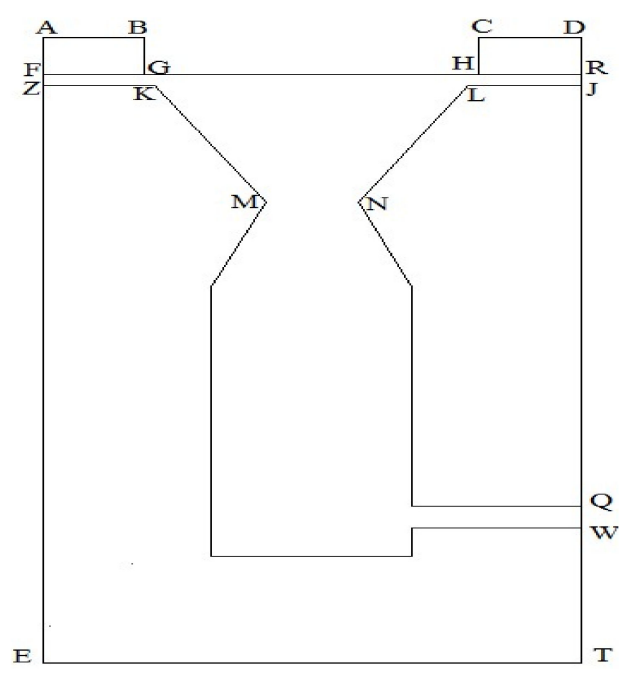

(a)

Figure 2. Cont. 

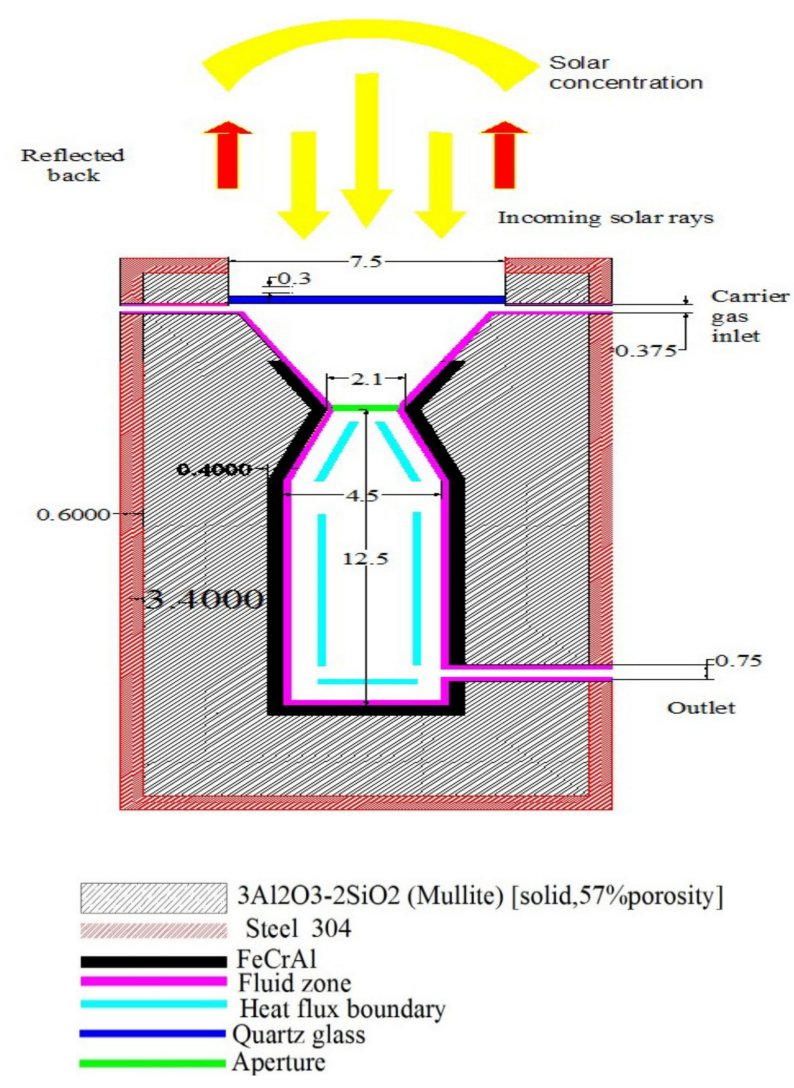

(b)

Figure 2. Schematic diagram of the heat storage reactor model: (a) Applied boundaries; (b) Computational domain used for the simulation.

The model had the following features: its top was conical and the bottom was rectangular; two opposite gas inlets each $0.375 \mathrm{~cm}$ in diameter (FZ and RJ) near to the quartz glass (GH); it had one outlet (QW) with diameter $0.75 \mathrm{~cm}$; it possessed a $0.3 \mathrm{~cm}$ thick quartz glass with 0.8 emissivity; the entire walls were insulated with $0.6 \mathrm{~cm}$ thick steel 304 (conductivity of $16.2 \mathrm{~W} / \mathrm{m} \cdot \mathrm{K}$, heat capacity of $500 \mathrm{~J} / \mathrm{kg} \cdot \mathrm{K}$ at $1600 \mathrm{~K}$ and density of $8000 \mathrm{~kg} / \mathrm{m}^{3}$ ); the inner wall was insulated with a high-temperature resistance metallic alloy, $\mathrm{FeCrAl}$ alloy with melting point close to $1800 \mathrm{~K}(0.4 \mathrm{~cm}$ thick and can withstand up to $2000 \mathrm{~K}$, thermal conductivity of $35 \mathrm{~W} / \mathrm{m} \cdot \mathrm{K}$ at $1600 \mathrm{~K}$, density of $7100 \mathrm{~kg} / \mathrm{m}^{3}$, heat capacity of $800 \mathrm{~J} / \mathrm{kg} \cdot \mathrm{K}$ at $1600 \mathrm{~K}$ and emissivity of 0.7 ) and the middle layer was insulated by $3.4 \mathrm{~cm}$ thick layer of $3 \mathrm{AlO}_{3}-2 \mathrm{SiO}_{2}$ (mullet, solid, $57 \%$ porosity, heat capacity of $840 \mathrm{~J} / \mathrm{kg} \cdot \mathrm{K}$ and temperature-dependent density and thermal conductivity). As shown in Figure 2b, the cavity had a width of $4.5 \mathrm{~cm}$, a height of $12.5 \mathrm{~cm}$, a receiver diameter of $7.5 \mathrm{~cm}$, and an aperture diameter of $2.1 \mathrm{~cm}$. Nitrogen was used as the carrier gas for the reactor and was also used for the removal of deposition of particles around the quartz glass region [22]. The gas particles enter the reactor in opposite directions with injected velocity and collide with each other. This collision is important to the loss of kinetic energy and heat conversion. Moreover, it makes the flow more stable, leading to more heat entering the reactor.

\subsection{Model Equations}

To predict the instantaneous temperature distribution and the fluid flow inside the reactor, a numerical model was developed by assuming the flow was laminar and the continuity conservation equation, momentum conservation equation, and energy conservation equation for the solar thermal 
energy reactor were calculated. Hence, the governing equations for the thermo-fluid flow inside the reactor are given by the following equations [31]:

$$
\begin{gathered}
\frac{\partial \rho}{\partial t}+\nabla \cdot(\rho u)=0 \\
\rho \frac{\partial u}{\partial t}+\rho(u \cdot \nabla) u=-\nabla P+\nabla\left[\mu\left(\Delta u+(\nabla u)^{T}\right)-\frac{2}{3} \mu \nabla u\right] \\
\rho c_{p} \frac{\partial T}{\partial t}+\rho C_{p} u \cdot \nabla T=\nabla \cdot u(k \nabla T)
\end{gathered}
$$

where $\rho, u, P, \mu, k, T$, and $C_{p}$ are density, velocity vector, pressure, dynamic viscosity, thermal conductivity, temperature, and specific heat, respectively.

In incorporating radiation into participating media, the conduction radiative heat flux is taken into consideration. According to these assumptions, the incident radiation flux intensity for $\mathrm{P}_{1}$ radiation models is calculated using:

$$
\mathrm{Q}_{r}=\nabla \mathrm{q}_{\mathrm{r}}=\kappa\left(\mathrm{G}-4 \pi \mathrm{I}_{\mathrm{b}}(T)\right)
$$

where $Q_{r}$ is the radiative heat source, $\mathrm{q}_{\mathrm{r}}$ is conductive heat flux, $\kappa$ is absorption coefficient, $\mathrm{I}_{\mathrm{b}}(T)$ radiation intensity, and $\mathrm{G}$ is incident flux.

The heat equation is written as:

$$
\begin{gathered}
C_{p}\left(\frac{\partial T}{\partial t}+u \cdot \nabla T\right)+\nabla \cdot q=\kappa\left(\mathrm{G}-4 \pi \mathrm{n} \sigma \mathrm{T}^{4}\right)+\alpha_{p} T\left(\frac{\partial P}{\partial t}+u \cdot \nabla P\right)+\tau: \nabla u+Q \\
\mathrm{I}_{b}(T)=\frac{n_{r}^{4} T^{4}}{\pi}
\end{gathered}
$$

where $\mathrm{n}_{\mathrm{r}}, \tau, \sigma$, and $\alpha_{p}$ are the index of refraction, viscous tensor, Boltzmann constant, and coefficient thermal expansion, respectively.

The balanced radiation transfer equation is found in the following Equations (7)-(10) [32,33].

$$
\frac{d I_{r, s}}{d s^{\prime}}=\nabla\left(I_{r, s}\right)=I_{b, r}-\left(k+\sigma_{r, s}\right) I_{r, s}-\frac{\sigma_{r, s}}{4 \pi} \int_{4 \pi} I_{r, s^{*}}\left(s^{*}, s\right) \Phi d \Omega^{*}
$$

where $\kappa$ and $\sigma_{s}$ are absorption and scattering coefficients, respectively.

The general radiation flux transfer in a medium can be described as:

$$
\mathrm{G}=\int I(\Omega) \mathrm{d} \Omega
$$

The heat source can be described by the following equations:

$$
\begin{gathered}
-\nabla\left(\nabla P_{1} \nabla G\right)=Q_{r} \\
D P_{1}=\frac{1}{3 \kappa+\sigma_{s}\left(3-\mathrm{a}_{1}\right)}
\end{gathered}
$$

where $\mathrm{a}_{1}$ is the linear Legendre coefficient of scattering phase function and $Q_{r}$ is the radiative heat source.

When the scattering is model $\mathrm{a}_{1}=0$, Equation (10) becomes:

$$
D P_{1}=\frac{1}{3 \kappa+3 \sigma_{s}}
$$


for $\sigma_{s}=0, D P_{1}=\frac{1}{3 \mathrm{k}}$ Equation (9) can be expressed as follows:

$$
\nabla\left(\nabla P_{1} \nabla G\right)=Q_{r}, \nabla \cdot\left(\frac{1}{3 \kappa} \nabla G\right)=\kappa G-4 \pi \varepsilon \sigma_{S B} T^{4}
$$

From Equation (4), it can be shown that the radiative heat transfer was added to the system as:

$$
-\nabla q_{r}=\kappa G-4 \pi \varepsilon \sigma_{S B} T^{4}
$$

\subsection{Boundary Conditions}

The boundary conditions are presented in Table 1

Table 1. Boundary conditions.

\begin{tabular}{cccc}
\hline Section & Boundary Type & Flow Rate $\mathbf{V}_{\mathbf{i}}$ & Energy \\
\hline Left inlet (FZ) & Laminar-Inlet & Laminar inflow rate & Temperature 293.15 (K) \\
\hline Right inlet (RJ) & Laminar-Inlet & $\begin{array}{c}\text { Laminar inflow } \\
\text { rate }(\mathrm{L} / \mathrm{h})\end{array}$ & Temperature 273.15(K) \\
\hline $\begin{array}{c}\text { Irradiated walls } \\
(\mathrm{KM}, \mathrm{LN}, \mathrm{GH})\end{array}$ & Walls & 0.0 & $q=\varepsilon\left(G-\sigma T^{4}\right)$ \\
\hline $\begin{array}{c}\text { External Boundaries } \\
(\mathrm{GB}, \mathrm{AF}, \mathrm{HC}, \mathrm{DR}, \mathrm{ZW}, \mathrm{JQ})\end{array}$ & Wall & 0.0 & $\mathrm{q}=\mathrm{h}\left(\mathrm{T}_{\text {ext }}-\mathrm{T}_{\mathrm{w}}\right)$ \\
\hline Quartz window $(\mathrm{GH})$ & Wall & 0.0 & $\mathrm{q}=\mathrm{h}\left(\mathrm{T}_{\text {ext }}-\mathrm{T}_{\mathrm{w}}\right)+\varepsilon_{\text {ext }} \sigma\left(\mathrm{T}_{\infty}-\mathrm{T}_{\mathrm{w}}\right)$ \\
\hline Outlet $(\mathrm{QW})$ & Pressure outlet & $\frac{\partial V_{i}}{\partial n}=0$ & $\frac{\partial T}{\partial n}=0$ \\
\hline
\end{tabular}

$\mathrm{q}, \mathrm{h}, \mathrm{T}_{\text {ext }}, \mathrm{T}_{\mathrm{w}}, \varepsilon_{\text {ext }}$ and $\sigma$ are heat flux, heat transfer coefficient, external temperature, wall temperature, emissivity and Stefan-Boltzmann, respectively.

In Table 1, the boundary conditions are mainly inlet boundary, irradiated wall boundary and quartz wall boundary. In terms of the inlet boundary, the inlet tubes were on straight line to the right and left sides of the frustum near to the quartz glass window GH. Nitrogen gas enters the reactor at both sides of the inlets FZ and RJ at $293.15 \mathrm{~K}$ and $1 \mathrm{~atm}$, where a gas flow rate of $1.8 \mathrm{~L} / \mathrm{h}$ was applied at each inlet. Thus, total flow rate of $3.6 \mathrm{~L} / \mathrm{h}$ was utilized by the reactor. With regards to the irradiated wall, the thermal energy storage reactor was vertically fixed as seen in Figure 2a. In this current study, though the reactor was vertically fixed, it is also possible to check the thermal performance of the reactor by comparing the applied heat source either on the boundary edges of the frustum or directly at the quartz edge. This is possible by assuming a change in the direction of the simulator (source of radiation) and focusing concentrated radiation on the edges of the frustum edges KM and LN or at quartz edge $\mathrm{GH}$ at different times. For the quartz glass wall, the ambient surroundings behaved as a black body. Heat flux condition of $100.0 \mathrm{~W} / \mathrm{m}^{2} \cdot \mathrm{K}$ was applied to the externally insulated walls AF, ZE, DR, JQ, WT, and TE as shown in Figure 2a, which reduced heat release to the environment, protected the cavity from extreme heat and optimized heat transfer inside the cavity. Hence, the net heat flux boundary condition was applied at these surfaces, as shown in Table 1, and the temperature flow in the cavity was uniform.

\subsection{Numerical Solution Methods}

The solar thermal energy transport and temperature distribution inside the reactor were calculated by selecting the defined radiation heat transfer $\mathrm{P}_{1}$ radiation model. This model was used to investigate the heat flux distribution along the reactor. Nitrogen gas used in this study was weakly compressible and the geometry was meshed using free triangular mesh in the COMSOL Multiphysics 5.3 software. The solar thermal energy distribution inside the reactor was simulated assuming that a steady-state solver was applied. The initial temperature at the beginning of the simulation was $293.15 \mathrm{~K}$, which includes the wall and cavity, and with the incoming nitrogen gas was $293.15 \mathrm{~K}$. The incoming 
flux was not varied throughout the process. The simulation involved the selection of appropriate boundaries (Table 1) and taking into account different inlet locations, laminar flow rates, heat source, and deriving data namely flow rate, conduction flux, convective flux, surface average temperature, outlet average temperature, etc. The concentrated solar irradiance intensity was considered as an energy source for raising the reactor temperature until the desired thermal energy flux was achieved. The diffused irradiance intensity at the target radiant received surface covered by a quartz glass was considered as a boundary condition for high-temperature radiant energy flow inlet. The incident radiation flux which was reflected and emitted from the cavity walls was assumed to be diffusely distributed throughout the reactor. The solutions were converged before corrections were made and the convergence criterion was $10^{-8}$.

\subsection{Model Validation}

Figure 3 shows that the reactor temperature distribution compared to that derived from the existing literature [34].

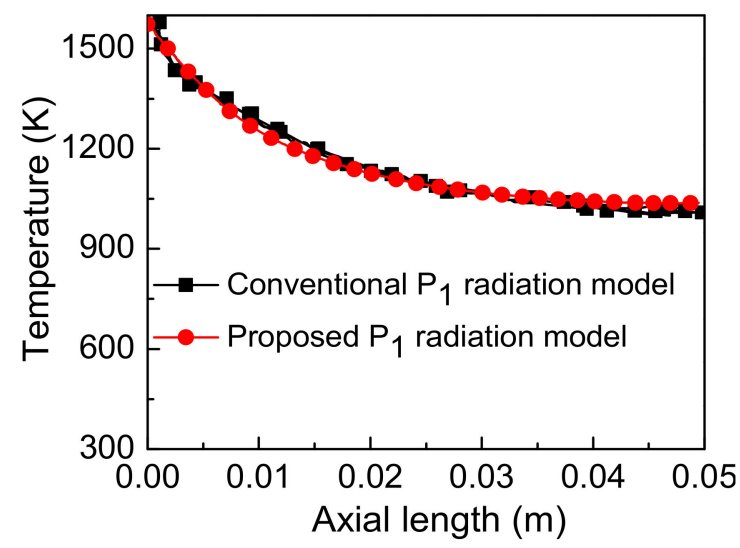

Figure 3. Temperature distribution compared to the Reference [34] under $170 \mathrm{~kW} / \mathrm{m}^{2}$ radiation heat flux applied on quartz glass at $8.64 \mathrm{~L} / \mathrm{h}$ inflow laminar and $1 \mathrm{~atm}$.

The simulation was conducted by considering $170 \mathrm{~kW} / \mathrm{m}^{2}$ radiation flux which was applied on the quartz glass edge GH with emissivity $(\varepsilon=0.8)$ from Figure 2 a and $8.64 \mathrm{~L} / \mathrm{h}$ laminar flow at $1 \mathrm{~atm}$. The calculated temperature distribution conformed to that presented in literature [34] as well as having the same $\mathrm{P}_{1}$ radiation model for $2 \mathrm{D}$ porous media. A maximum absolute error of $3 \%$ was found between reference data and the data presented in this study (Figure 3). This indicates that the present model can effectively analyse temperature distribution.

\subsection{Grid Independency Tests}

The governing equations were solved using the finite element technique based on COMSOL Multiphysics 5.3 software. A grid-independent test was conducted on the mesh model at the beginning of the simulation process. In Figure $4 \mathrm{a}$, it can be seen that the mesh used in this present study was a free triangular user-controlled mesh. Table 2 indicates the characteristics of the mesh. From Figure $4 \mathrm{~b}$, it can be seen how heat transferred through quartz glass then to the cavity. In Figure 4c, by applying $150 \mathrm{~kW} / \mathrm{m}^{2}$ radiation heat flux, $1.8 \mathrm{~L} / \mathrm{h}$ and $1 \mathrm{~atm}, 5$ mesh (models 7236, 23129, 152129, 355666 and 729576) were developed and it was found that the meshes 152129, 355666 and 729576 were good models for the study. Based on the objectives of this study, mesh 152129 met the minimum requirement and was utilised for subsequent investigations. 


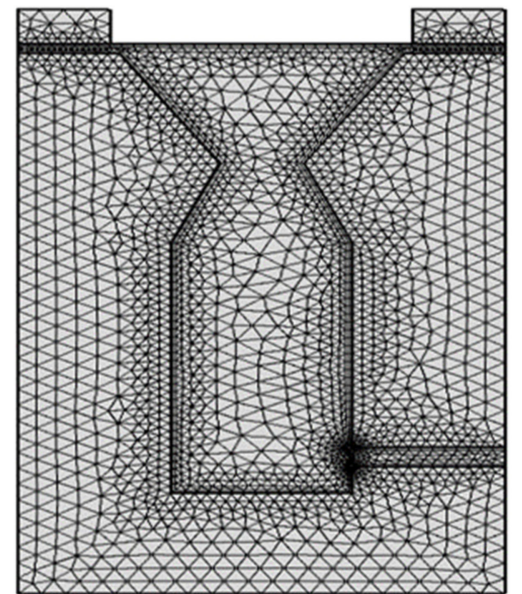

(a)

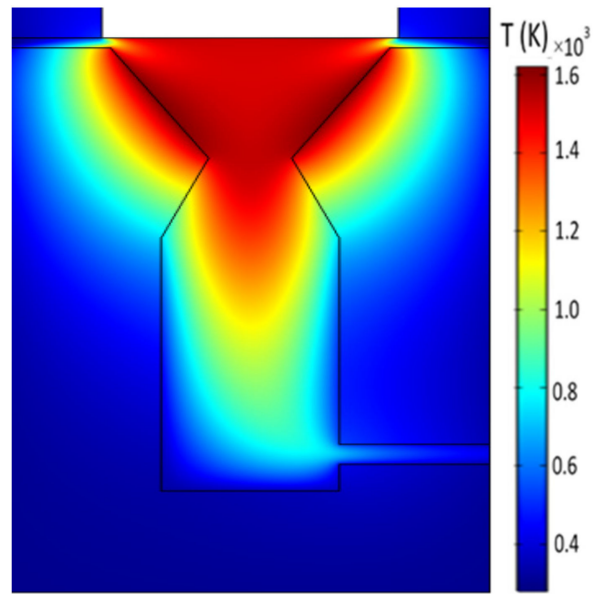

(b)

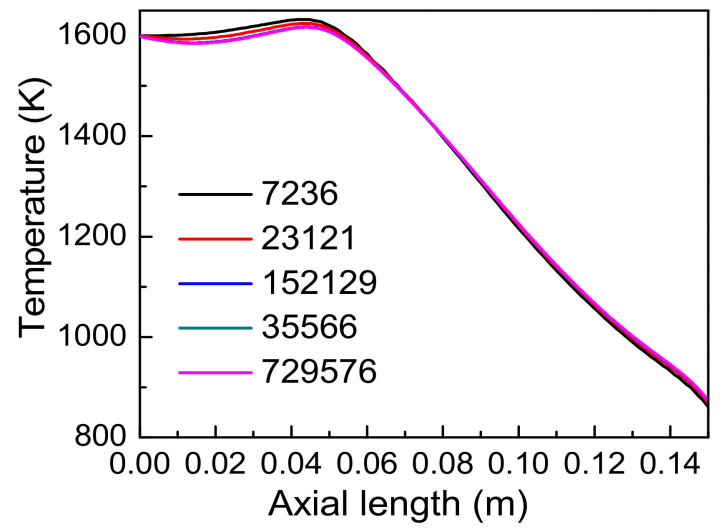

(c)

Figure 4. Grid independent analysis at $150 \mathrm{~kW} / \mathrm{m}^{2}$ radiation heat flux, $1 \mathrm{~atm}$ and $1.8 \mathrm{~L} / \mathrm{h}$ gas laminar inflow rate: (a) Cross-sectional view of mesh; (b) Temperature distribution along the axial length; and (c) Temperature distribution with different cell number.

Table 2. Mesh characteristics user-controlled mesh.

\begin{tabular}{cccccccc}
\hline $\begin{array}{c}\text { Maximum } \\
\text { Element } \\
\text { Size }(\mathbf{m m})\end{array}$ & $\begin{array}{c}\text { Minimum } \\
\text { Element } \\
\text { Size }(\mathbf{m m})\end{array}$ & $\begin{array}{c}\text { Maximum } \\
\text { Element } \\
\text { Growth Rate }\end{array}$ & $\begin{array}{c}\text { Resolution } \\
\text { Narrow } \\
\text { Region }\end{array}$ & $\begin{array}{c}\text { Curvature } \\
\text { Factor }\end{array}$ & $\begin{array}{c}\text { Minimum } \\
\text { Element } \\
\text { Quality }\end{array}$ & $\begin{array}{c}\text { Average } \\
\text { Element } \\
\text { Quality }\end{array}$ & $\begin{array}{c}\text { Element } \\
\text { Length } \\
\text { Ratio }\end{array}$ \\
\hline 0.657 & 0.001 & 1.300 & 1.000 & 0.300 & 0.568 & 0.957 & 0.938 \\
\hline
\end{tabular}

\section{Result and Discussion}

The current study investigated the thermal performance of nitrogen gas-filled cavity with different insulation materials. The impact of gas inlet position along the boundary on the frustum and outlet at the bottom and the side of the cavity was also studied. The reactor was directly exposed to $150 \mathrm{~kW} / \mathrm{m}^{2}$ radiation heat flux and applied boundaries are highlighted in Table 1.

\subsection{Impact of Applied Heat Resource Frustum Edges and Quartz Edge Using Varying Simulator Direction for Thermal Performance of the Reactor}

The evaluation of the thermal performance of the reactor was done by changing the direction of the heat source released from the simulator and focusing it on the frustum and quartz glass edges. The performance evaluation was done by applying $150 \mathrm{~kW} / \mathrm{m}^{2}$ heat source to the edge of quartz glass GH (Figure 2a) and to the edges of frustum KM and LN (Figure 5a). It was found that the radiation flux applied at boundaries of the frustum was highly reflected and concentrated around $0.043 \mathrm{~m}$ 
from quartz glass edge GH. This occurred because the focus point for the diffused radiation at edges of frustum was close to the aperture and $0.043 \mathrm{~m}$ from edges of the quartz glass. From the results, the temperature drop around the aperture for the heat source applied to the frustum edge was less than that of the quartz glass edge. It was also observed that high radiation loss occurred around the radiation inlet region for heat source applied to the quartz glass, which was due to re-irradiation around radiation inlet region. The radiation heat source applied on the frustum was highly important because of the less temperature drop around radiation inlet region and aperture region. This led to improvement of the thermal performance of the reactor. It was observed in Figure $5 b$ that the surface average temperature was greater for the radiation flux applied to the frustum edges than that applied to quartz edge at different laminar inflow rates. In Figure $5 c$, the surface average temperature was greater for the frustum applied heat source. Overall, Figure $5 \mathrm{a}-\mathrm{c}$ indicate that the thermal performance of the reactor was good when radiation was applied at frustum edges and focused at $0.043 \mathrm{~m}$ from the quartz glass edge.

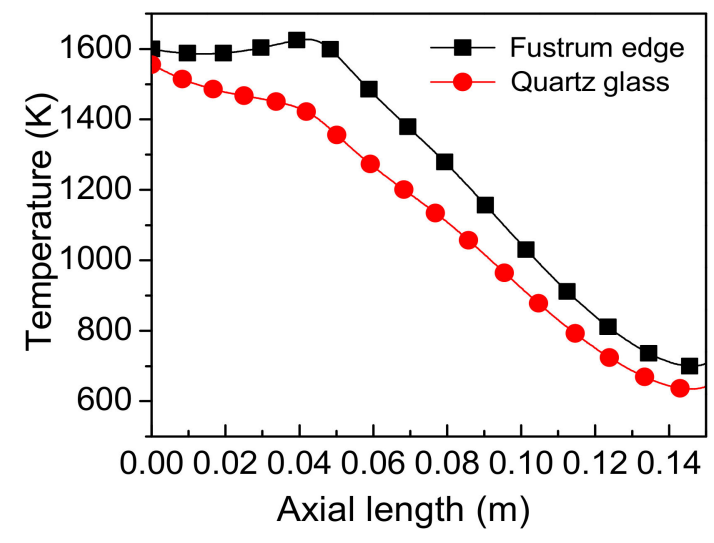

(a)

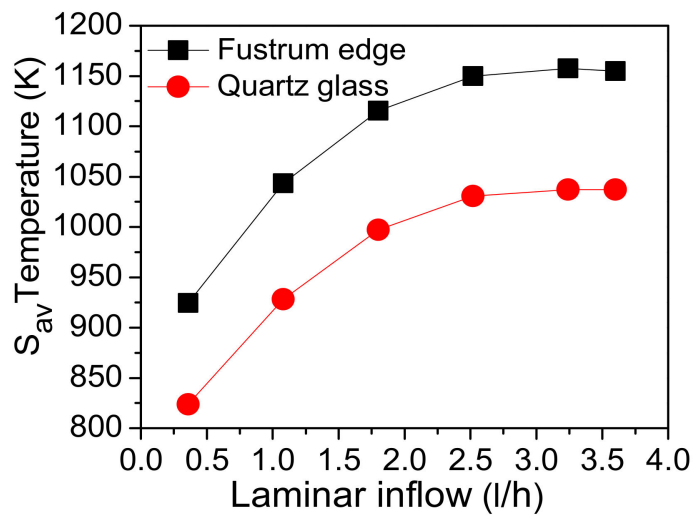

(b)

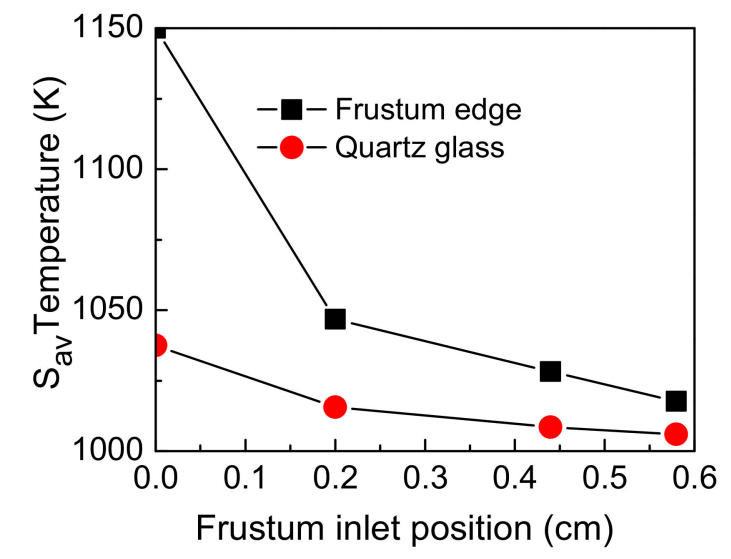

(c)

Figure 5. Temperature distribution in the cavity along axial length at $150 \mathrm{~kW} / \mathrm{m}^{2}, 1 \mathrm{~atm}$ and $1.81 / \mathrm{h}$ laminar inflow rate: (a) Temperature distribution flux applied on frustum edge and quartz edge; $(\mathbf{b})\left(\mathrm{S}_{\mathrm{av}}\right)$ temperature at different laminar inflow rates; $(\mathbf{c})\left(\mathrm{S}_{\mathrm{av}}\right)$ temperature at different gas inlet positions of radiation flux applied on frustum and quartz glass edges.

\subsection{Impact of Outlet Position on Temperature Distribution}

From Figure 6a, as laminar inflow rate increased from 0.36 to $2.52 \mathrm{~L} / \mathrm{h}$, the bottom outlet geometry's surface average temperature distribution was found to be slightly identical to the side outlet geometry's average temperature. When the laminar inflow rate increased from 2.88 to $3.60 \mathrm{~L} / \mathrm{h}$, the bottom outlet geometry's surface average temperature was slightly greater than the side outlet geometry's surface average temperature, but both increased linearly with increase in laminar inflow rate. In Figure 6b, 
it can be observed that the outlet average temperature for the side outlet geometry was greater than that of the bottom outlet geometry average temperature. Further increasing the applied heat source on the frustum edges led to a higher rate in the increase of surface average temperature than that of the average outlet temperature. For a fixed applied radiation flux, it was noted that increase in the laminar inflow rate increased the average outlet temperature at a higher rate when compared with that of the surface average temperature.

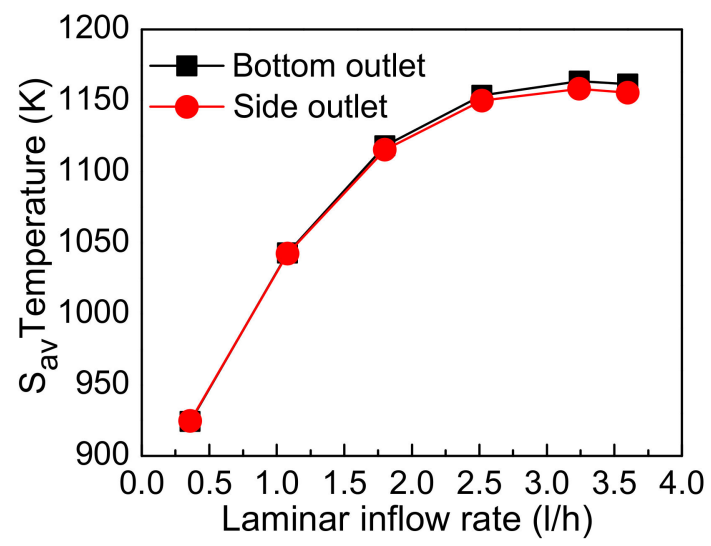

(a)

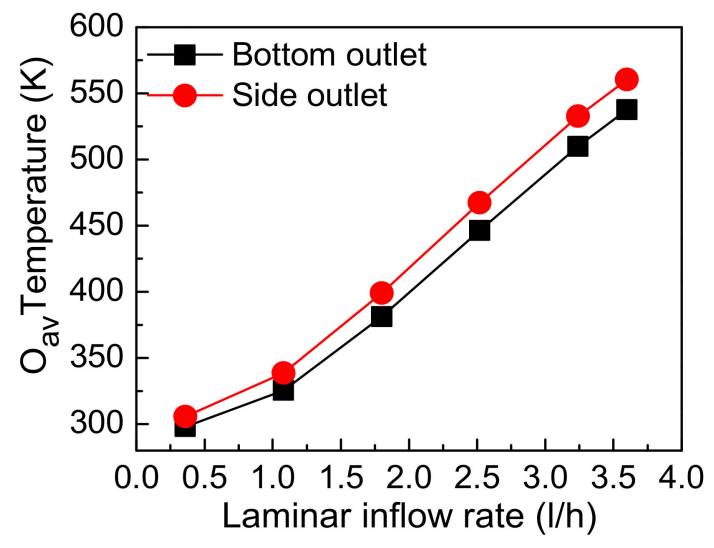

(b)

Figure 6. The average temperature for different laminar inflow rate at $150 \mathrm{~kW} / \mathrm{m}^{2}$ and $1 \mathrm{~atm}$ : (a) Surface average temperature and (b) Outlet average temperature.

Figure $7 \mathrm{a}, \mathrm{b}$ show the temperature distribution along the central axis of the reactor for both types of outlet locations.

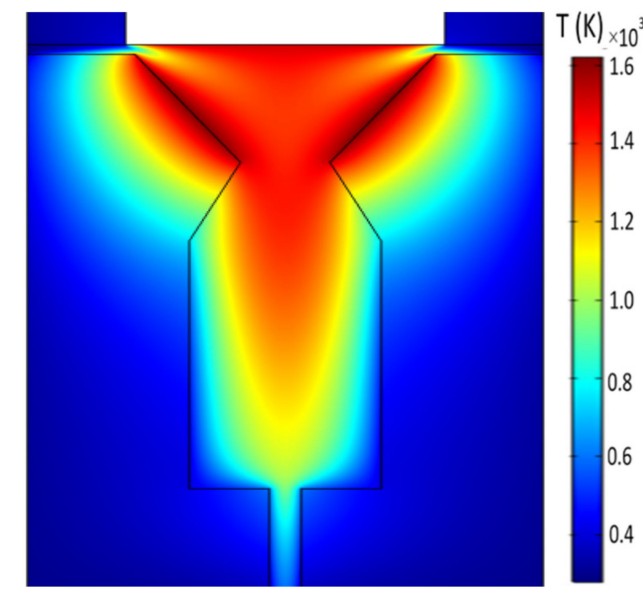

(a)

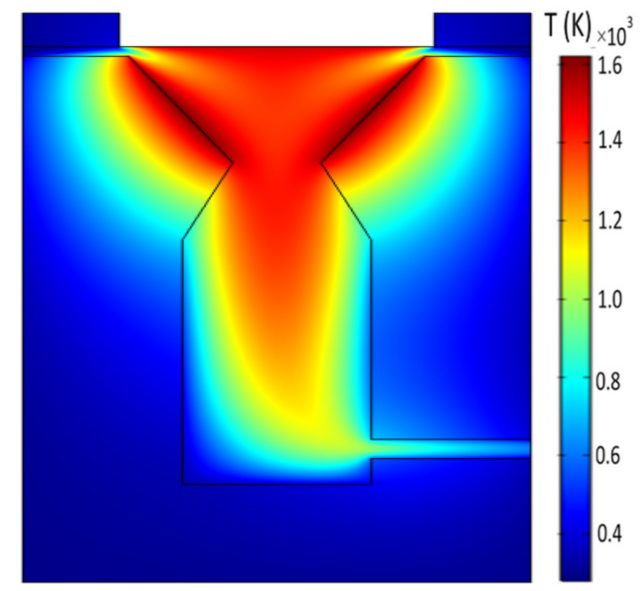

(b)

Figure 7. Temperature distribution along the axial length at $3.6 \mathrm{~L} / \mathrm{h}$ flow rate and $150 \mathrm{~kW} / \mathrm{m}^{2}$ applied radiation flux on frustum edge: (a) bottom outlet geometry and (b) side outlet geometry.

\subsection{Incident Radiation Heat Flux and the Radiation Temperature Distribution}

The simulation was carried out by applying $150 \mathrm{~kW} / \mathrm{m}^{2}$ radiation flux on frustum edges $\mathrm{KM}$ and $\mathrm{LN}$ in Figure $2 \mathrm{~b}$. The laminar inflow rate was considered as $1.8 \mathrm{~L} / \mathrm{h}$ at $1 \mathrm{~atm}$ and nitrogen gas as fluid. In Figure 8 a, it can be seen that the incident radiation flow in the reactor was non-uniform. 


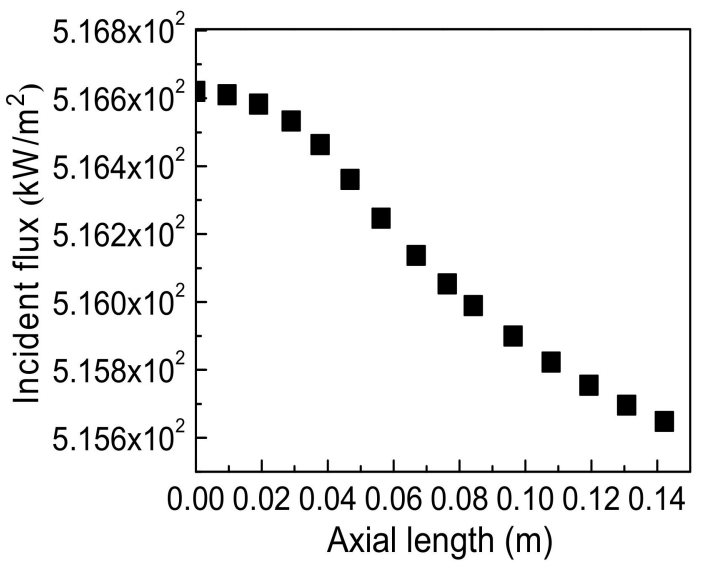

(a)

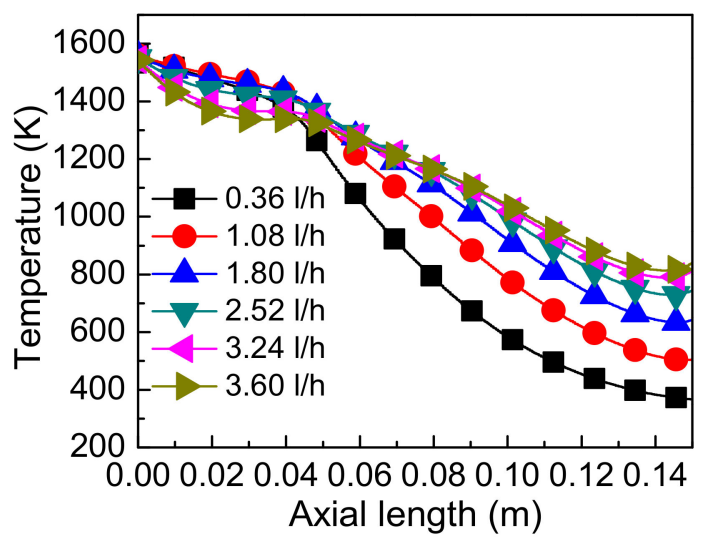

(c)

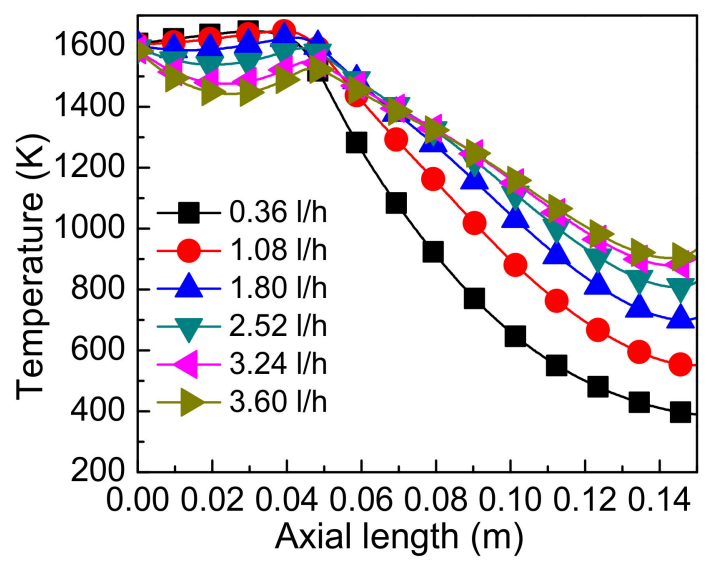

(b)

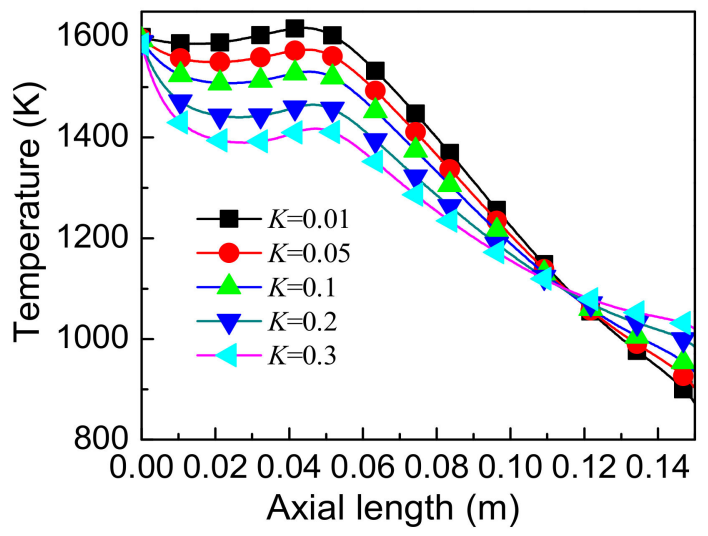

(d)

Figure 8. The distribution flux along the reactor at $150 \mathrm{~kW} / \mathrm{m}^{2}$ incident flux, 1 atm and $1.8 \mathrm{~L} / \mathrm{h}$ inflow rate: (a) Incident heat flux distribution in the reactor at $1.8 \mathrm{~L} / \mathrm{h}$ and $\mathrm{K}=0.3$; (b) Temperature distribution for flux applied on frustum edges KM and LN; (c) Temperature distribution for the flux applied at (GH) for different gas inflow rate; (d) Temperature distribution for different absorption coefficient $(K)$.

The applied fluxes and other boundaries are shown in Table 1. Although the flux was diffused on the edges of the frustum and quartz in Table 1, the maximum temperature occurred not on the edge of the quartz but around $0.043 \mathrm{~m}$ from the quartz glass or near to the aperture region. This occurrence was due to the flux being focused near to this region. It was found that the high flux concentration occurred around $0.043 \mathrm{~m}$ from the quartz glass edge and this concentration decreased slowly until the end of the reactor length at $0.125 \mathrm{~m}[8,12,35]$. This decrease in temperature was compensated by the absorption of nitrogen gas and an increase in the inflow rate inside the reactor. It can be observed in Figure 8a that the radiation flux was not completely reduced or absorbed due to the slow absorption [36-38]. In this region, the incoming radiation flow and convective heat transfer flow due to the carrier gas were highly distributed before converging at the reactor outlet. This impingement of gas flow and absorption both play significant roles in the absorption of the incoming flux inside the reactor since the heat transfer is the limiting factor to oxygen release [39]. The absorption coefficient level of nitrogen gas for this current study was chosen as 0.01 and from Figure $8 d$, it is shown that increasing the absorption coefficients from 0.01 to 0.3 increased the absorption of the temperature inside the cavity and decrease in the temperature in the aperture region. Similarly, from Figure 8b, increasing the inflow rate from 0.36 to $3.6 \mathrm{~L} / \mathrm{h}$ increased the absorption temperature in the cavity but decreased the temperature in the aperture region. This can be attributed to more radiation flux moving from a higher region to a lower region on the axial length. The decrease in radiation heat flux is advantageous to re-irradiation losses from the back wall where the reactor cross-section decreases. This flow and the decrease in the radiation heat 
flux facilitated the absorption of more energy into the reactor. This occurrence was due to the proper insulation of the reactor which decreased conduction heat loss. The temperature distribution along the reactor is a function of laminar inflow rate, absorption [12] and emission coefficient. The carrier gas flow in the reactor heated up and transferred the heat into the reactor. The rapid increment of temperature resulted in the absorption of radiation heat flux and the distribution shifted towards the inner cavity. The temperature distribution in the cavity was highly influenced by the laminar inflow rate and absorption coefficients of the gas. The gradual reduction of radiation temperature with increase in absorption coefficients is related to the effects of convective heat transfer between fluid and cavity wall due to the carrier gas [40,41]. However, in the current study and from Figure $8 \mathrm{a}$, the overall result indicated that the temperature did not completely decrease inside the reactor before converging at the reactor outlet. Moreover, the temperature gradually decreased along with decrease in incident radiation intensity as well as with increase in reactor axial length. However, the higher results may be attributed to the increase in gas laminar inflow rate of the reactor.

\subsection{Effect of Thermal Performance of Inlet Location on Edges of Frustum}

In Figure 9a, the distribution temperature was more uniform for the fluid inlets located near the top of the frustum, and as a result, more incident flux was absorbed around this region. Whereas, the temperature distribution for other inlet regions below the top and near to the base of frustum fluid inlets location had the lowest thermal performance in the cavity. In Figure $9 b$, the inlets position shifted $0.58 \mathrm{~cm}$ from the top region of the frustum and the flux entering the quartz edge of the cavity decreased in the cavity. In Figure $9 c, d$, the maximum convective heat transfer and velocity distributions occurred at inlets located $4.4 \mathrm{~cm}$ from the base the frustum. This was because, at the top region, re-irradiation of the quartz glass edges GH, AG, and DH occurred. For other inlet regions, as the inlets shifted from the base, both velocity and convective heat transfer decreased as shown in Figure $9 b, c$, respectively. In Figure 9e, the conduction heat transfer was least in the top region while at maximum at the base region. It is inferred that the top inlet region was appropriate in improving the optimal thermal performance in the thermal energy storage cavity.

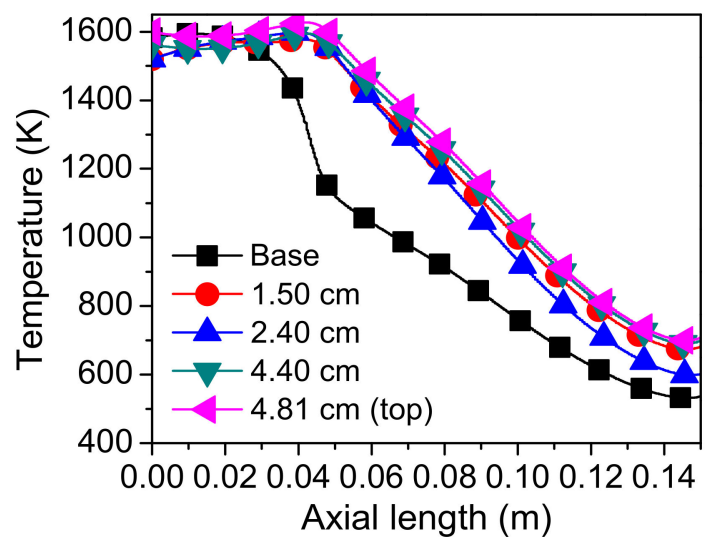

(a)

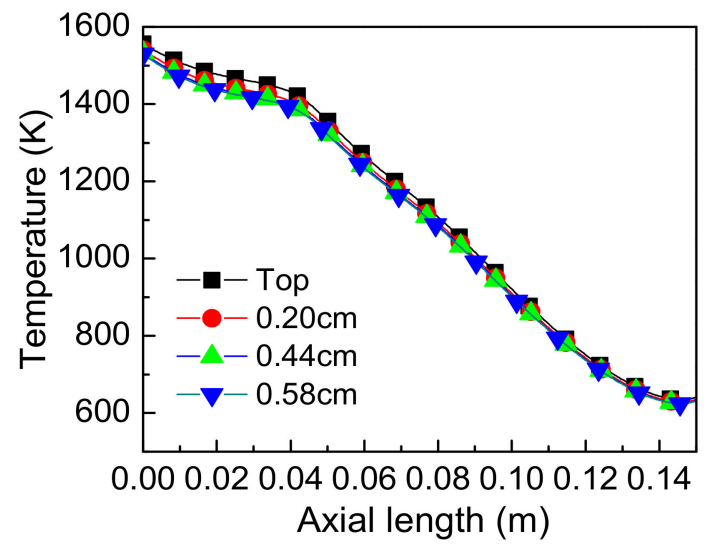

(b)

Figure 9. Cont. 


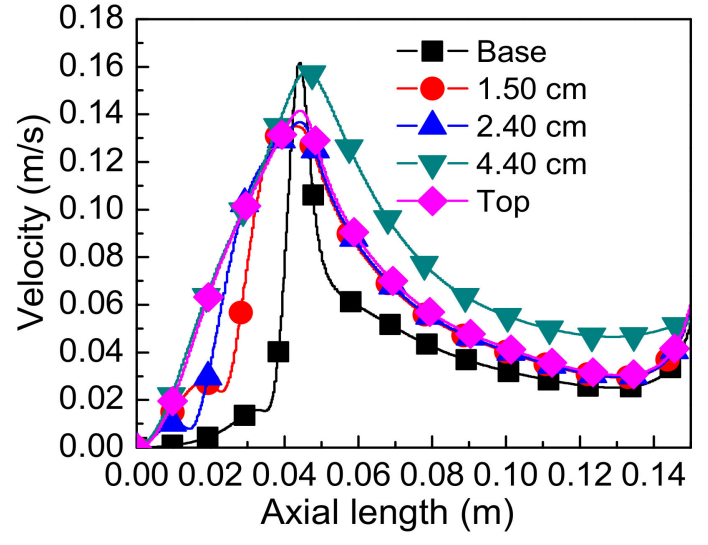

(c)

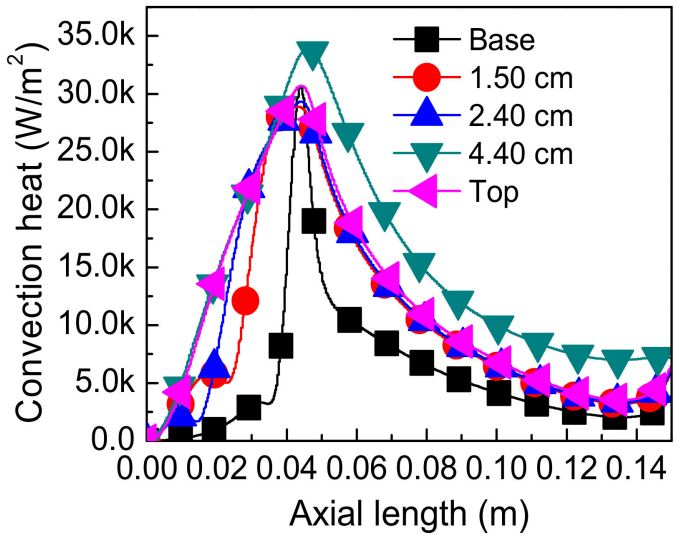

(d)

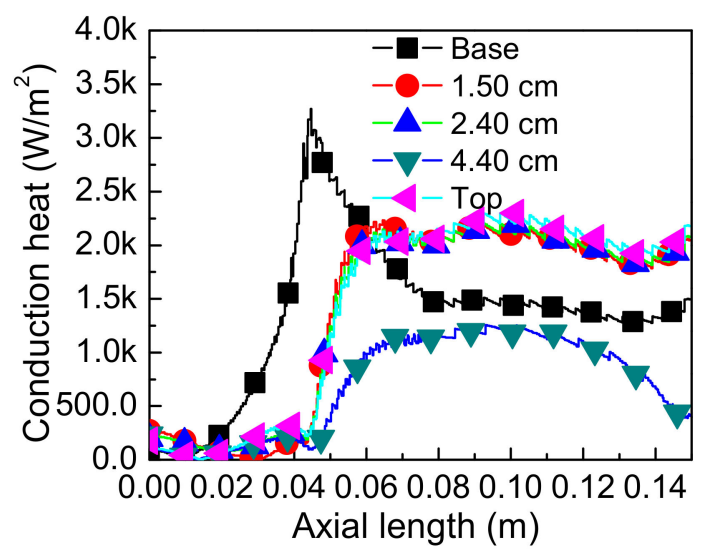

(e)

Figure 9. The distribution flux along the reactor at $150 \mathrm{~kW} / \mathrm{m}^{2}$ incident flux. $1 \mathrm{~atm}$ and $1.8 \mathrm{~L} / \mathrm{h}$ for different fluid inlet positions: (a) Temperature distribution of the inlet positions from the base frustum; (b) Temperature distribution of the inlet positions from the top of the frustum; (c) Velocity distribution of inlets from the base of the frustum; (d) Convective heat flow distribution of the inlets from the base of the frustum and (e) Conduction heat transfer of the inlets from the base of the frustum.

\subsection{Impacts of Inlet Tube Location and Its Insulation Condition}

From Figure 10, it can be seen that at the same inputs, but at different inlet tube locations and insulation alterations in the temperature distribution in the reactor, were observed.

As the inlet tubes were located at the applied heat source region and its insulated material projected above the quartz glass (Figure 10a), it was found that the temperature distribution was more uniform than those of the inlet tubes located below the quartz edges at opposite ends. It was also observed in Figure 10b,c that both average outlet and surface average temperatures were greater for inlets at quartz glass edges than those below the quartz edges. Inlet tubes located at the quartz glass edges near to the applied heat source were more prone to absorb more heat and less susceptible to re-irradiation. Moreover, the chance of re-irradiation and solid deposition were less than those at the inlet tubes located below the quartz edge. It is seen in Figure 10d that there was no temperature concentrated at the quartz boundary, however, in Figure 10e, the temperature was concentrated around the quartz glass boundary which was not transferred to the reactor and thus, was available for re-irradiation. Thus, it can be deduced that not only the reactor inlets located at quartz glass edges were important, but the proper insulation of inlet tubes located at the edge of the quartz glass was also a determinant factor for uniform temperature distribution in the cavity (Figure 10d). This is important for a uniform temperature distribution and the enhancement of high temperature in the reactor cavity. 


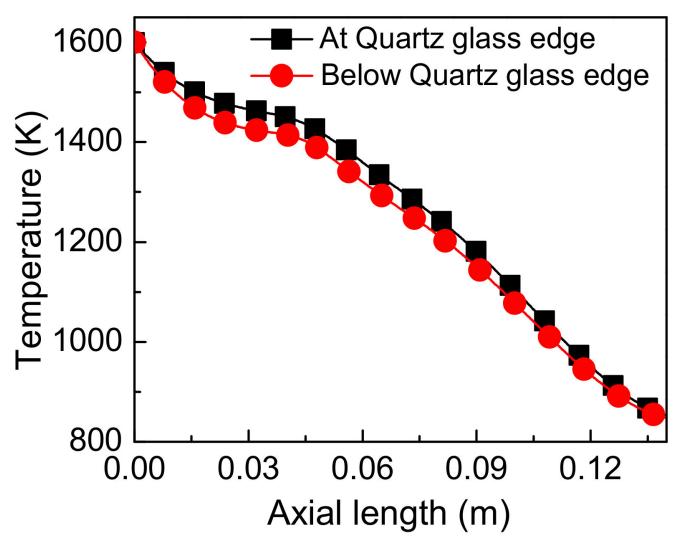

(a)

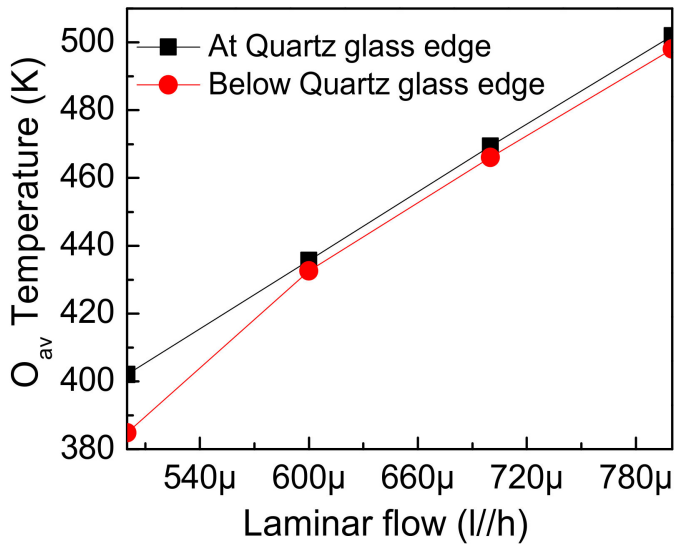

(b)

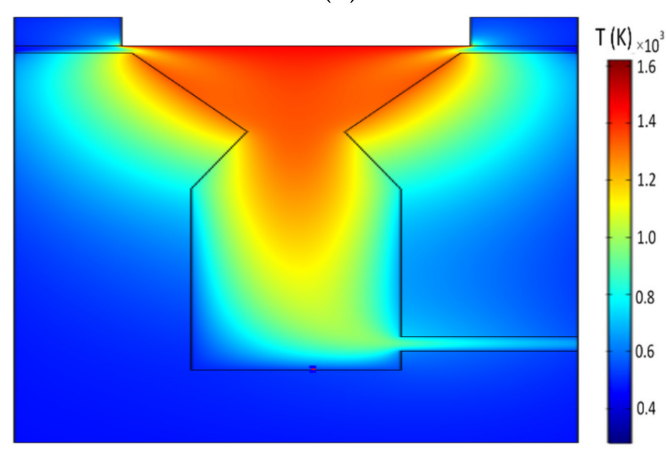

(d)

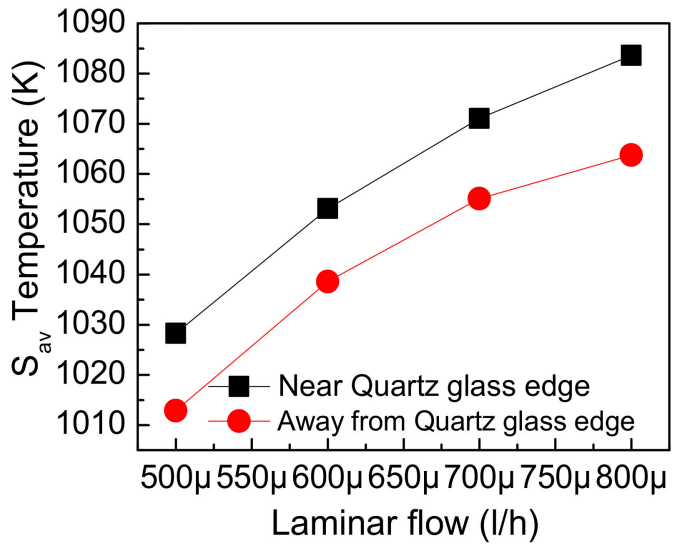

(c)

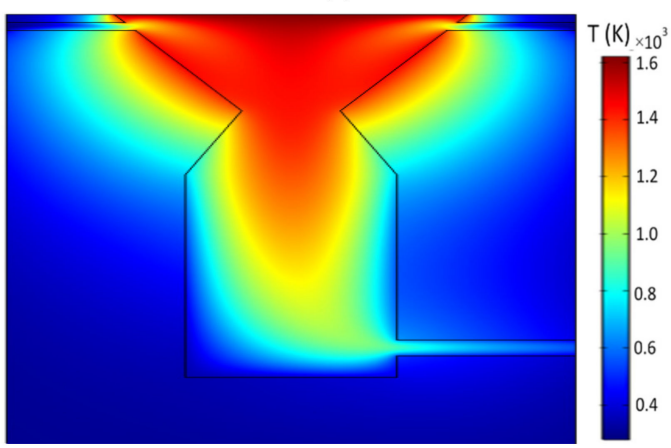

(e)

Figure 10. Temperature distribution along the axial length of inlet tubes at the edge of quartz glass and below the edge of quartz glass at $2.88 \mathrm{~L} / \mathrm{h}$ flow rate and $1600 \mathrm{~K}$ applied at quartz edge: (a) Axial temperature distribution and (b) Side outlet average temperature; (c) Average surface temperature; (d) Axial temperature distribution of inlets at the quartz glass edge and (e) Axial temperature distribution of inlets below the quartz glass edge.

\subsection{Effect of Fluid on Thermal Performance of Storage Reactor}

The fluid is one of the key components in establishing an energy storage system for absorbing solar energy. The mass flow rate of solid and fluid particles affect axial temperature distribution inside reactor [42]. In Figure 11, it is assumed that four gasses are weakly compressible fluids and the scattering and absorption coefficients were $\sigma_{s}=0$ and $\kappa=0.01$, respectively. These gases, as inlet fluids, were investigated for their thermal performance in the reactor. The results revealed that helium showed the lowest performance while methane showed the best performance. Helium had the lowest temperature absorption capacity while argon and nitrogen both had similar high-temperature 
absorption capacities (Figure 11). Also, methane was better in absorbing flux. In general, the thermal performance of a reactor is affected by the fluids which directly absorbed solar energy.

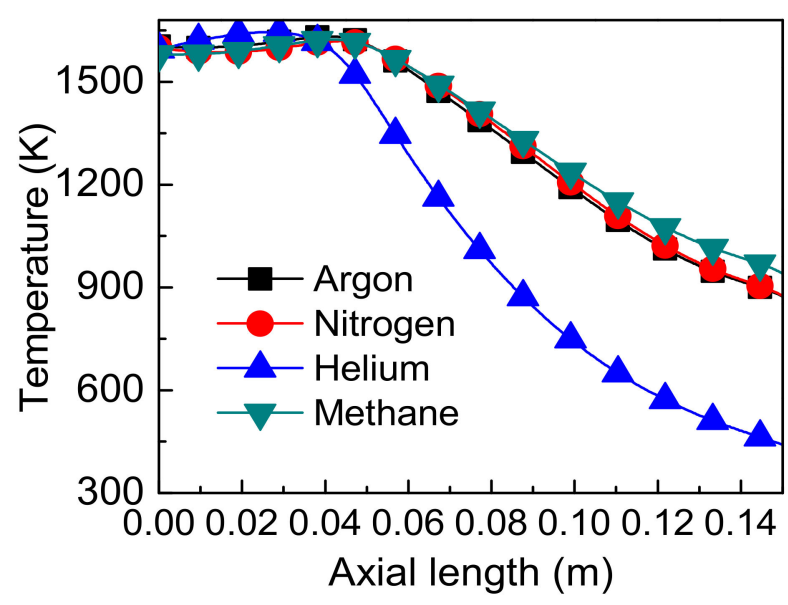

Figure 11. The distribution of temperature in the cavity of different gases at absorption $=0.01$, $150 \mathrm{~kW} / \mathrm{m}^{2}$ radiation flux source and $1 \mathrm{~atm}$.

\subsection{Effect of Wall Cavity Insulation Materials on Thermal Performance}

In Figure 12, different wall insulation materials were compared for their performance in achieving uniform temperature distribution in the cavity, the properties of $\mathrm{FeCrAl}(0.4 \mathrm{~cm}$ thick at an emissivity of $\varepsilon=0.7$ ) and $\mathrm{Y}_{2} \mathrm{O}_{3}$ and $\mathrm{ZrO}_{2}$ felt (felt, air $5700 \mathrm{Kg} / \mathrm{m}^{3}$ [43] and the physical properties of $\mathrm{Al}_{2} \mathrm{O}_{3}$ and $\mathrm{CaO}$ were extrapolated from COMSOL libraries. As can be observed in Figure 12a, from 0.0 to $0.043 \mathrm{~cm}$, the temperature distributions of $\mathrm{FeCrAl}$ and $\mathrm{CaO}$ (overlapped each other) were lower than $\mathrm{Y}_{2} \mathrm{O}_{3}$-stabilised $\mathrm{ZrO}_{2}$ felt, (felt, air) and $\mathrm{Al}_{2} \mathrm{O}_{3}$. From 0.043 to $0.1 \mathrm{~m}$, the temperature distributions of $\mathrm{FeCrAl}$ and $\mathrm{CaO}$ were greater than $\mathrm{Al}_{2} \mathrm{O}_{3}$ and $\mathrm{Y}_{2} \mathrm{O}_{3}$-stabilised $\mathrm{ZrO}_{2}$ felt, (felt, air). However, from 0.1 to $0.15 \mathrm{~m}$, the temperature distribution of $\mathrm{Al}_{2} \mathrm{O}_{3}$ was greater. In Figure $12 \mathrm{~b}$, the surface average temperature and outlet average temperature of $\mathrm{Al}_{2} \mathrm{O}_{3}(1131.8 \mathrm{~K}$ and $403.62 \mathrm{~K}$, respectively) were greater than those of other materials.

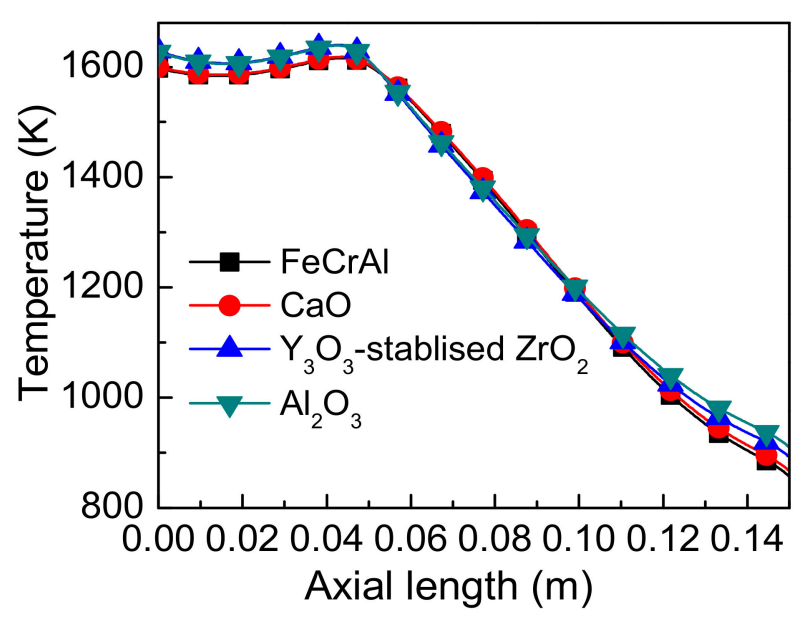

(a)

Figure 12. Cont. 


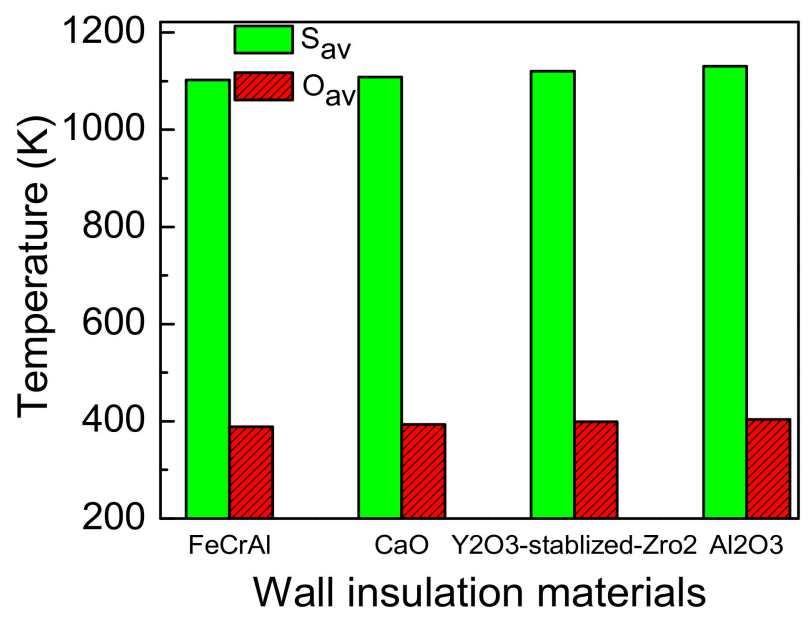

(b)

Figure 12. The temperature distribution at $150 \mathrm{~kW} / \mathrm{m}^{2}, 1 \mathrm{~atm}, 1.8 \mathrm{~L} / \mathrm{h}$ and 0.7 emissivity: (a) Temperature distribution along the axial length of different wall insulation materials and (b) the surface average $\left(\mathrm{S}_{\mathrm{av}}\right)$ and outlet average $\left(\mathrm{O}_{\mathrm{av}}\right)$ temperatures of different wall insulation materials.

\subsection{Instantaneous Temperature Distribution}

Temperature distribution is a function of time, thus, as time increases, the absorbed temperature inside the cavity increases. In Figure 13a, as time increased from 10 to $90 \mathrm{~min}$, the distribution of concentrated flux around the frustum region in the reactor axis was initiated and reached a maximum at $90 \mathrm{~min}$. In Figure 13b, both the surface average temperature and average outlet temperature increased from 600 to $3000 \mathrm{~s}$. However, from $3000 \mathrm{~s}$ onwards, the average outlet and surface average temperature became constant. This indicates that effective absorption took place at 3000 to $5400 \mathrm{~s}$. Figure $13 \mathrm{c}$ indicates the temperature distribution in the cavity at different times (10, 25, 50, and $90 \mathrm{~min})$.

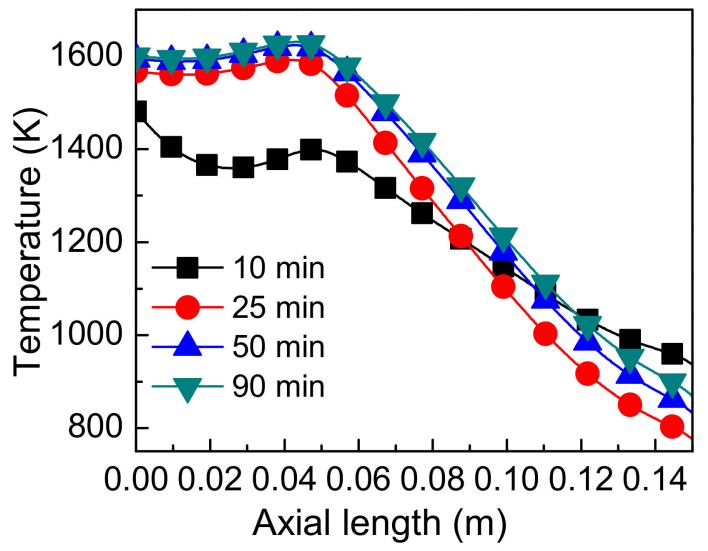

(a)

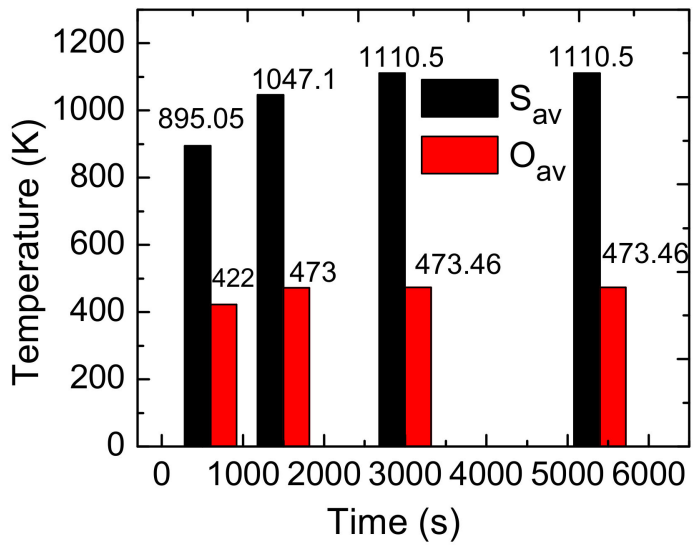

(b)

Figure 13. Cont. 


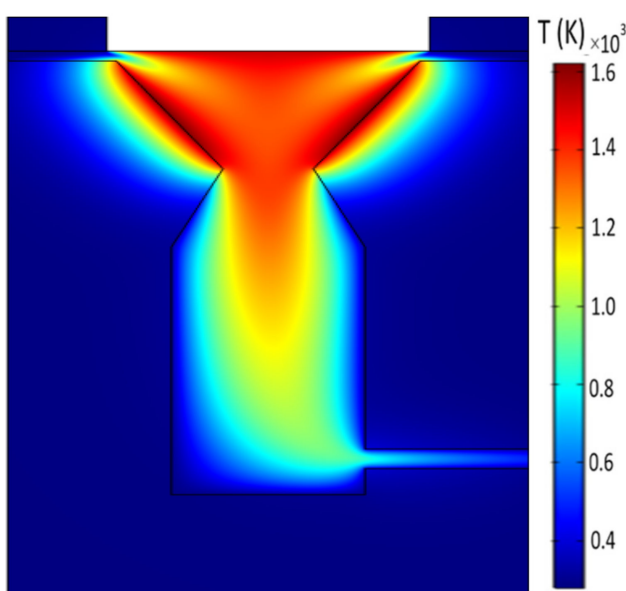

$10 \mathrm{~min}$

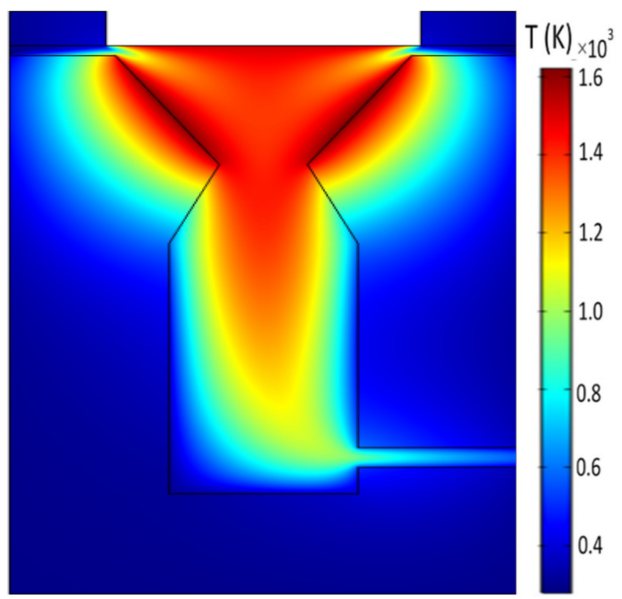

$50 \mathrm{~min}$

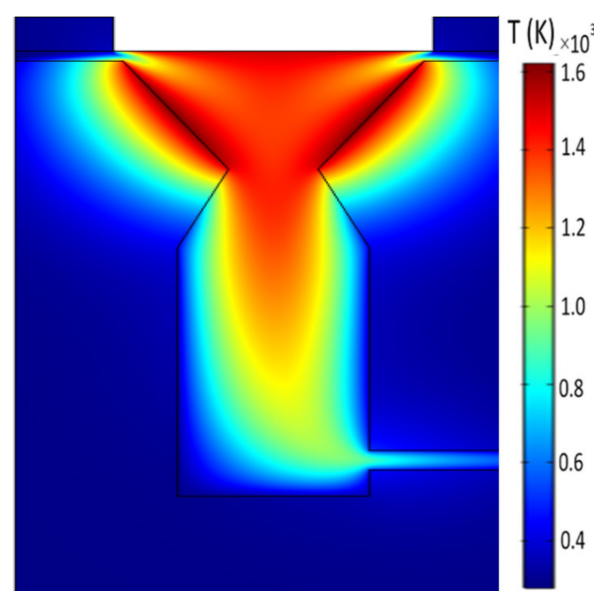

$25 \mathrm{~min}$

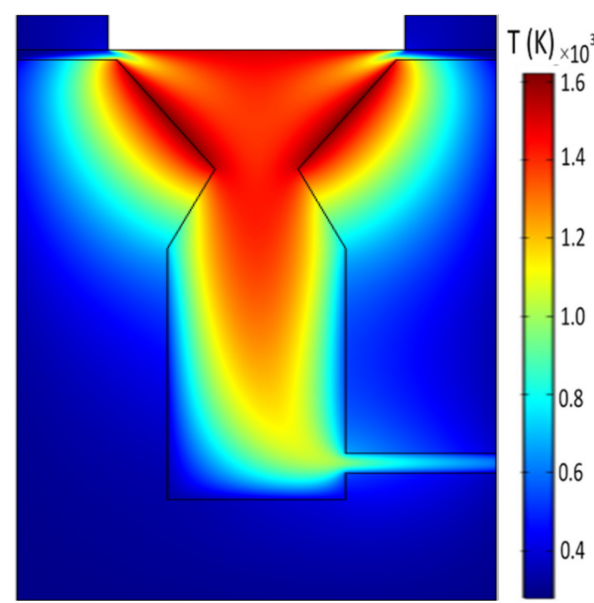

$90 \mathrm{~min}$

(c)

Figure 13. The instantaneous distribution temperature at $150 \mathrm{~kW} / \mathrm{m}^{2}, 1 \mathrm{~atm}$ and $3.6 \mathrm{~L} / \mathrm{h}$ : (a) Temperature distribution; (b) Bar chart illustrating the outlet average and surface average temperatures in the cavity and (c) Thermal imagery showing the instantaneous distribution of temperature inside the reactor at different times.

\section{Conclusions}

The location of the fluid inlet on the edges of the frustum and the fluid position outlets on the cavity are both vital to the thermal performance of a solar cavity. Situating both the inlet tube location of a reactor at quartz glass edges and the proper insulation of the inlet tube located at quartz glass within the frustum was important for a uniform temperature distribution and the enhancement of high-temperature attainment by a reactor. Furthermore, the positioning of the gas inlet at a distance of $4.81 \mathrm{~cm}$ from the base of reactor frustum edges increases the temperature propagation inside the cavity. The diffused flux on the edges of the frustum for incident radiation concentrated at a distance of $4.3 \mathrm{~cm}$ from the quartz glass or near to the aperture was able to significantly decrease aperture temperature drop and increase thermal performance. Moreover, increasing the laminar flow up to 3.6 L/h increased temperature penetration in the cavity. The designed side outlet cavity attained greater outlet temperature than that of the designed bottom outlet cavity. However, laminar flow greater than $3.6 \mathrm{~L} / \mathrm{h}$ exposed the receiver to conduction loss thereby reducing the thermal performance of a reactor. Therefore, to withstand high-temperature flow inside a solar cavity, the thickness and insulation material used for the construction of walls in a reactor should be properly considered and the geometry of the reactor should be optimised. 
Author Contributions: All authors contributed to the attainment of this work as follows: Formal analysis, investigation, data curation, writing-original draft presentation data, writing-review, Y.G.D.; conceptualization, methodology, supervision, validation, and funding acquisition, B.G.L. and H.Q.; software, J.Z., B.G., and M.A.I.; visualization, H.T. All authors have read and agreed to the published version of the manuscript.

Funding: This work was funded by the National Natural Science Foundation of China (No. 51976044; 51950410590), China Postdoctoral Science Foundation Fund (2019M651284), and Fundamental Research Funds for the Central Universities (HIT.NSRIF.2020054).

Acknowledgments: The authors appreciate the contributions, anonymous contributors, in terms of their moral and technical support in enhancing the quality of this work.

Conflicts of Interest: The authors declare no conflict of interest and the funders had no role in the design of the study; in the collection, analyses, or interpretation of data; in the writing of the manuscript, or in the decision to publish the results.

\section{Nomenclature}

$\begin{array}{lll}\mathrm{C}_{\mathrm{P}} & \text { Specific heat capacity } & \mathrm{J} /(\mathrm{kg} \cdot \mathrm{K}) \\ \mathrm{G} & \text { Incident radiation intensity } & \mathrm{W} / \mathrm{m}^{2} \\ \mathrm{~T} & \text { Temperature } & \mathrm{K} \\ \mathrm{H} & \text { Heat conductivity } & \mathrm{W} /\left(\mathrm{m}^{2} / \mathrm{K}\right) \\ \mathrm{P} & \text { Pressure } & \mathrm{Pa} \\ \mathrm{K} & \text { Thermal conductivity } & \mathrm{J} /(\mathrm{m} \cdot \mathrm{K}) \\ \mathrm{U} & \text { Velocity vector } & \mathrm{m} / \mathrm{s} \\ \mathrm{F} & \text { Body force vector } & \mathrm{N} / \mathrm{m}^{2} \\ \mathrm{Q}_{\mathrm{rad}} & \text { Radiation heat source } & \mathrm{W} / \mathrm{m}^{3} \\ \mathrm{n}_{\mathrm{r}} & \text { Refraction index } & - \\ \mathrm{I} & \text { Radiation intensity } & \mathrm{W} /\left(\mathrm{m}^{2} \cdot \mathrm{sr}^{-1}\right) \\ \mathrm{Greek} & \text { symbol } & \\ \rho & \text { Fluid density } & \mathrm{kg} / \mathrm{m}^{3} \\ \alpha_{p} & \text { Coefficient of thermal expansion } & 1 / \mathrm{K} \\ \kappa & \text { Absorption constant } & 1 / \mathrm{m}^{3} \\ \varepsilon & \text { Emissivity } & \mathrm{m} \cdot \mathrm{s}^{-3} \\ \sigma_{S B} & \text { Stefan-Boltzmann constant } & \mathrm{W} /\left(\mathrm{m}^{2} \cdot \mathrm{K}^{4}\right) \\ \mu & \text { Dynamic viscosity } & \mathrm{Pa} \cdot \mathrm{s} \\ \sigma_{S} & \text { Scattering coefficient } & 1 / \mathrm{m}\end{array}$

\section{References}

1. Mao, Q. Recent developments in geometrical configurations of thermal energy storage for concentrating solar power plant. Renew. Sust. Energ. Rev. 2016, 59, 320-327. [CrossRef]

2. Mahfuz, M.H.; Anisur, M.R.; Kibria, M.A.; Saidur, R.; Metselaar, I.H.S.C. Performance investigation of thermal energy storage system with Phase Change Material (PCM) for solar water heating application. Int. Commun. Heat Mass. 2014, 57, 132-139. [CrossRef]

3. Mao, Q.; Shuai, Y.; Yuan, Y. Study on radiation flux of the receiver with a parabolic solar concentrator system. Energ. Convers. Manage. 2014, 84, 1-6. [CrossRef]

4. Mao, Q.; Chen, H.; Zhao, Y.; Wu, H. A novel heat transfer model of a phase change material using in solar power plant. Appl. Therm. Eng. 2018, 129, 557-563. [CrossRef]

5. Romero, M.; Steinfeld, A. Concentrating solar thermal power and thermochemical fuels. Energy Environ. Sci. 2012, 5, 9234-9245. [CrossRef]

6. Kodama, T.; Gokon, N. Thermochemical cycles for high-temperature solar hydrogen production. Chem. Rev. 2007, 107, 4048-4077. [CrossRef]

7. Meier, A.; Ganz, J.; Steinfeld, A. Modeling of a novel high-temperature solar chemical reactor. Chem.Eng. Sci. 1996, 51, 3181-3186. [CrossRef]

8. Steinfeld, A.; Schubnell, M. Optimum aperture size and operating temperature of a solar cavity-receiver. Sol. Energy 1993, 50, 19-25. [CrossRef] 
9. Steinfeld, A.; Palumbo, R. Solar thermochemical process technology. Encycl. Phys. Sci.Technol. 2001, 15, 237-256.

10. Schunk, L.O.; Haeberling, P.; Wepf, S.; Wuillemin, D.; Meier, A.; Steinfeld, A. A receiver-reactor for the solar thermal dissociation of zinc oxide. J. Sol.Energy Eng. 2008, 130, 021009. [CrossRef]

11. Sturzenegger, M.; Nüesch, P. Efficiency analysis for a manganese-oxide-based thermochemical cycle. Energy 1999, 24, 959-970. [CrossRef]

12. Bellan, S.; Alonso, E.; Gomez-Garcia, F.; Perez-Rabago, C.; Gonzalez-Aguilar, J.; Romero, M. Thermal performance of lab-scale solar reactor designed for kinetics analysis at high radiation fluxes. Chem.Eng. Sci. 2013, 101, 81-89. [CrossRef]

13. Gardon, R. An instrument for the direct measurement of intense thermal radiation. Rev. Sci. 1953, 24, 366-370. [CrossRef]

14. Gómez, F.; Gonzalez-Aguilar, J.; Romero, M. Experimental 3D flux distribution of a 7 kWe-solar simulator. In Proceedings of the SolarPACES Conference, Granada, Spain, 20-23 September 2011.

15. Kenisarin, M.M. High-temperature phase change materials for thermal energy storage. Renew. Sust. Energ. Rev. 2010, 14, 955-970. [CrossRef]

16. Yuan, Y.; Ruan, Z.-H.; Huang, X.; Jiang, Y.-Q.; Tan, H.-P. Energy-absorption-based explanation of the $\mathrm{TiO}_{2} / \mathrm{C}$ photocatalytic activity enhancement mechanism. J. Catal. 2017, 348, 246-255. [CrossRef]

17. Fuqiang, W.; Ziming, C.; Jianyu, T.; Yuan, Y.; Yong, S.; Linhua, L. Progress in concentrated solar power technology with parabolic trough collector system: A comprehensive review. Renew. Sust. Energ. Rev. 2017, 79, 1314-1328. [CrossRef]

18. Medrano, M.; Gil, A.; Martorell, I.; Potau, X.; Cabeza, L.F. State of the art on high-temperature thermal energy storage for power generation. Part 2-Case studies. Renew. Sust. Energ. Rev. 2010, 14, 56-72. [CrossRef]

19. Zalba, B.; Marín, J.M.; Cabeza, L.F.; Mehling, H. Review on thermal energy storage with phase change: Materials, heat transfer analysis and applications. Appl. Therm. Eng. 2003, 23, 251-283. [CrossRef]

20. Bie, Y.; Li, M.; Chen, F.; Królczyk, G.; Yang, L.; Li, Z.; Li, W. A novel empirical heat transfer model for a solar thermal storage process using phase change materials. Energy 2019, 168, 222-234. [CrossRef]

21. Bie, Y.; Li, M.; Malekian, R.; Chen, F.; Feng, Z.; Li, Z. Effect of phase transition temperature and thermal conductivity on the performance of Latent Heat Storage System. Appl. Therm. Eng. 2018, 135, 218-227. [CrossRef]

22. Lougou, B.G.; Shuai, Y.; Chen, X.; Yuan, Y.; Tan, H.; Xing, H. Analysis of radiation heat transfer and temperature distributions of solar thermochemical reactor for syngas production. Front. Energy 2017, 11, 480-492. [CrossRef]

23. Lougou, B.G.; Shuai, Y.; Guohua, Z.; Chaffa, G.; Ahouannou, C.; Tan, H. Analysis of $\mathrm{H}_{2}$ and CO production via solar thermochemical reacting system of $\mathrm{NiFe}_{2} \mathrm{O}_{4}$ redox cycles combined with $\mathrm{CH}_{4}$ partial oxidation. Int. J. Hydrog. Energy 2018, 43, 5996-6010. [CrossRef]

24. Lougou, B.G.; Shuai, Y.; Zhang, J.; Huang, X.; Yuan, Y.; Tan, H. Syngas production by simultaneous splitting of $\mathrm{H}_{2} \mathrm{O}$ and $\mathrm{CO}_{2}$ via iron oxide $\left(\mathrm{Fe}_{3} \mathrm{O}_{4}\right)$ redox reactions under high-pressure. Int. J. Hydrog. Energy 2016, 41, 19936-19946.

25. Lougou, B.G.; Shuai, Y.; Chaffa, G.; Xing, H.; Tan, H.; Du, H. Analysis of $\mathrm{CO}_{2}$ utilization into synthesis gas based on solar thermochemical $\mathrm{CH}_{4}$-reforming. J. Energy Chem. 2019, 28, 61-72. [CrossRef]

26. Harris, J.A.; Lenz, T.G. Thermal performance of solar concentrator/cavity receiver systems. Sol. Energy 1985, 34, 135-142. [CrossRef]

27. Reddy, K.S.; Vikram, T.S.; Veershetty, G. Combined heat loss analysis of solar parabolic dish-Modified cavity receiver for superheated steam generation. Sol. Energy 2015, 121, 78-93. [CrossRef]

28. Le Roux, W.G.; Bello-Ochende, T.; Meyer, J.P. Operating conditions of an open and direct solar thermal Brayton cycle with optimised cavity receiver and recuperator. Energy 2011, 36, 6027-6036. [CrossRef]

29. Prakash, M. Numerical study of natural convection heat loss from cylindrical solar cavity receivers. Renew. Energy 2014, 2014, 1-7. [CrossRef]

30. Singh, A.; Lapp, J.; Grobbel, J.; Brendelberger, S.; Reinhold, J.P.; Olivera, L.; Ermanoski, I.; Siegel, N.P.; McDaniel, A.; Roeb, M.; et al. Design of a pilot scale directly irradiated, high temperature, and low pressure moving particle cavity chamber for metal oxide reduction. Sol. Energy 2017, 157, 365-376. [CrossRef]

31. Bellan, S.; Alonso, E.; Perez-Rabago, C.; Gonzalez-Aguilar, J.; Romero, M. Numerical modeling of solar thermochemical reactor for kinetic analysis. Energy Procedia 2014, 49, 735-742. [CrossRef] 
32. Cheng, P. Two-dimensional radiating gas flow by a moment method. Am. Inst. Aeronaut. Astronaut. 1964, 2 , 1662-1664. [CrossRef]

33. Cheng, P. Dynamics of a radiating gas with application to flow over a wavy wall. Am. Inst. Aeronaut. Astronaut. 1966, 4, 238-245. [CrossRef]

34. Wang, F.; Shuai, Y.; Tan, H.; Yu, C. Thermal performance analysis of porous media receiver with concentrated solar irradiation. Int. J. Heat Mass Transf. 2013, 62, 247-254. [CrossRef]

35. Palumbo, R.; Keunecke, M.; Möller, S.; Steinfeld, A. Reflections on the design of solar thermal chemical reactors: Thoughts in transformation. Energy 2004, 29, 727-744. [CrossRef]

36. Abanades, S.; Flamant, G. Production of hydrogen by thermal methane splitting in a nozzle-type laboratory-scale solar reactor. Int. J. Hydrog. Energy 2005, 30, 843-853. [CrossRef]

37. Suter, S.; Steinfeld, A.; Haussener, S. Pore-level engineering of macroporous media for increased performance of solar-driven thermochemical fuel processing. Int. J. Heat Mass Transf. 2014, 78, 688-698. [CrossRef]

38. Alonso, E.; Pérez-Rábago, C.; González-Aguilar, J.; Romero, M. A novel lab-scale solar reactor for kinetic analysis of non-volatile metal oxides thermal reductions. Energy Procedia 2014, 57, 561-569. [CrossRef]

39. Costandy, J.; El Ghazal, N.; Mohamed, M.T.; Menon, A.; Shilapuram, V.; Ozalp, N. Effect of reactor geometry on the temperature distribution of hydrogen producing solar reactors. Int. J. Hydrog. Energy 2012, 37, 16581-16590. [CrossRef]

40. Müller, R.; Haeberling, P.; Palumbo, R.D. Further advances toward the development of a direct heating solar thermal chemical reactor for the thermal dissociation of $\mathrm{ZnO}$ (s). Sol. Energy 2006, 80, 500-511. [CrossRef]

41. Ackermann, S.; Takacs, M.; Scheffe, J.; Steinfeld, A. Reticulated porous ceria undergoing thermochemical reduction with high-flux irradiation. Int. J. Heat Mass Transf. 2017, 107, 439-449. [CrossRef]

42. Lougou, B.G.; Shuai, Y.; Pan, R.; Chaffa, G.; Ahouannou, C.; Zhang, H.; Tan, H. Radiative heat transfer and thermal characteristics of Fe-based oxides coated SiC and Alumina RPC structures as integrated solar thermochemical reactor. Sci. China Technol. Sci. 2018, 61, 1788-1801. [CrossRef]

43. Bellouard, Q.; Rodat, S.; Abanades, S.; Ravel, S.; Frayssines, P.-É. Design, simulation and experimental study of a directly-irradiated solar chemical reactor for hydrogen and syngas production from continuous solar-driven wood biomass gasification. Int. J. Hydrog. Energy 2019, 44, 19193-19205. [CrossRef] 